\title{
The effects of water restriction and water loading on urinary excretion of lead, $\delta$-aminolevulinic acid and coproporphyrin ${ }^{1}$
}

\author{
S. ARAKI ${ }^{2}$
}

From the Department of Public Health, School of Medicine, Faculty of Medicine, University of Tokyo, Hongo, Bunkyo-ku, Tokyo, Japan

ABSTRACT Alterations in daily urinary excretion of lead, $\delta$-aminolevulinic acid (ALA), coproporphyrin, creatinine and total solutes following water restriction and water loading were examined in nine lead workers. Excretion of lead, ALA and total solutes was significantly decreased when urinary volume was reduced, showing that these values are dependent on urinary volume: conversely, excretion of coproporphyrin and creatinine was independent of urinary volume. Excretion of lead and total solutes was also dependent on creatinine excretion. The renal excretory mechanism of lead, ALA and coproporphyrin is discussed in the light of these findings.

The renal excretory mechanism of lead, $\delta$-aminolevulinic acid (ALA) and coproporphyrin has not been fully elucidated. There is evidence that plasma lead is filtered at the glomerulus (Vostál, 1963) and is also secreted from the tubules in chickens (Vostál and Heller, 1968). Renal clearance of plasma lead is extremely low in man (Molyneux, 1964). These observations suggest that plasma lead is filtered at the glomerulus and then largely reabsorbed by the tubules. There is little, if any, tubular secretion of lead in man. The pattern of renal excretion of lead may differ between precipitable and non-precipitable lead (Kawai, 1976).

Under normal physiological conditions, 90-95\% of the ALA filtered is thought to be reabsorbed in the tubules (Druyan et al., 1965; Suzuki and Suzuki, 1974). The reabsorption rate decreases with increased serum ALA concentration (Berlin et al., 1956; Druyan et al., 1965). The possibility that toxic damage to the renal tubules may contribute to the decreased reabsorption rate has been excluded

${ }^{1}$ This paper is based on part of a dissertation submitted for the degree of MSc in Occupational Medicine at the London School of Hygiene and Tropical Medicine, University of London.

'Present address: Department of Public Health, Tohoku University School of Medicine, Seiryo-machi, Sendai, Japan.

Received for publication 9 January 1978

Accepted for publication 23 February 1978 by animal experiments (Johnson et al., 1976). Two mechanisms have been put forward to explain the excretory mechanism of coproporphyrin: filtration of coproporphyrinogen at the glomerulus (Miura, 1971), and tubular secretion of coproporphyrinogen (Suzuki and Suzuki, 1966). In either situation, coproporphyrin is formed by auto-oxidation of coproporphyrinogen during its passage through the urinary tract.

Some reports have suggested that urinary excretion of lead may increase in proportion to urinary volume (Webster, 1941; Taguchi et al., 1972; Sakurai and Kagawa, 1973). As the levels of urinary lead, ALA and coproporphyrin, together with blood lead and erythrocyte free protoporphyrin and ALA dehydratase, are commonly considered to be definitive in the evaluation of lead absorption, it is necessary to assess any alteration in their excretion with changed urinary volume.

In this report, special attention is paid to the reabsorptive mechanism of lead, ALA and coproporphyrin in the renal tubules; the alteration in their urinary excretion following marked changes in urinary volume has been examined by means of water restriction and water loading.

\section{Subjects and methods}

SUBJECTS

The nine subjects (volunteers) were male lead workers. Their age, specific occupations, blood lead 
Table 1 Subjects and renal function

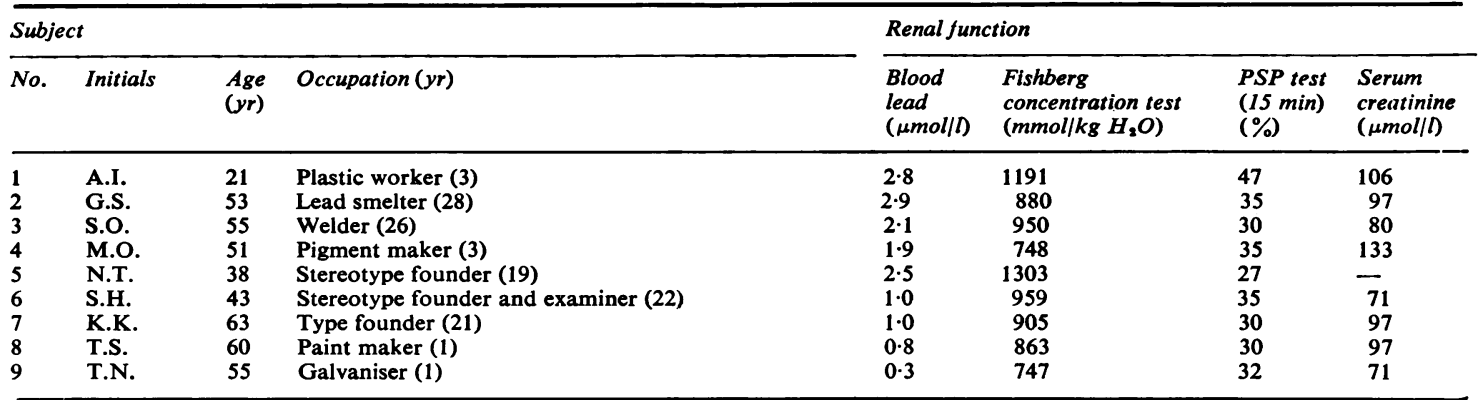

Table 2 Daily variation in urinary excretion of lead, ALA, coproporphyrin, creatinine and total solutes following water restriction and water loading

\begin{tabular}{|c|c|c|c|c|c|c|c|c|c|c|}
\hline \multirow[t]{3}{*}{ Urinary excretion } & \multicolumn{9}{|l|}{ Subjects } & \multirow{3}{*}{$\begin{array}{l}\text { Orerall } \\
\text { mean }\end{array}$} \\
\hline & A.I. & $G . S$. & S.O. & M.O. & N.T. & S.H. & $\boldsymbol{K} . \boldsymbol{K}$. & $T . S$. & T.N. & \\
\hline & (6) & (6) & (6) & (6) & (6) & (5) & (10) & (6) & (6) & \\
\hline \multicolumn{11}{|l|}{ Lead $(\mu \mathrm{mol} / 24 \mathrm{~h})$} \\
\hline Mean & $1 \cdot 80$ & 0.41 & $0 \cdot 32$ & $0 \cdot 37(4)$ & $0 \cdot 26$ & $0 \cdot 24$ & $0 \cdot 17$ & $0 \cdot 13$ & $0 \cdot 11(3)$ & 0.42 \\
\hline SD & 0.30 & $c \cdot 14$ & 0.07 & 0.04 & 0.05 & $0 \cdot 14$ & 0.03 & 0.03 & 0.02 & 0.09 \\
\hline \multicolumn{11}{|l|}{ ALA $(\mu \mathrm{mol} / 24 \mathrm{~h})$} \\
\hline Mean & 37 & 18 & 10 & 一 & 17 & 26 & 15 & 31 & 14 & 21 \\
\hline SD & 16 & 3 & 4 & - & 4 & 21 & 6 & 8 & 4 & 8 \\
\hline \multicolumn{11}{|c|}{ Coproporphyrin ( $\mu \mathrm{mol} / 24 \mathrm{~h})$} \\
\hline Mean & $0 \cdot 239$ & 0.086 & 0.040 & 一 & $0 \cdot 151$ & $0 \cdot 122$ & 0.040 & 0.096 & $0 \cdot 104$ & $0 \cdot 110$ \\
\hline SD & 0.072 & 0.026 & 0.017 & - & 0.024 & 0.047 & 0.012 & 0.023 & 0.055 & 0.035 \\
\hline \multicolumn{11}{|c|}{ Creatinine (mmol/24 h) } \\
\hline Mean & $16 \cdot 9$ & $10 \cdot 4(4)$ & $9 \cdot 8(4)$ & $9 \cdot 5$ & 一 & $11 \cdot 8$ & - & $11 \cdot 1$ & $11 \cdot 1$ & $11 \cdot 5$ \\
\hline SD & $2 \cdot 2$ & $2 \cdot 0$ & $2 \cdot 0$ & $1 \cdot 4$ & 一 & $1 \cdot 3$ & 一 & $1 \cdot 1$ & $\mathbf{2} \cdot \mathbf{3}$ & $1 \cdot 8$ \\
\hline \multicolumn{11}{|c|}{ Total solutes $(\mathrm{g} / 24 \mathrm{~h}) \dagger$} \\
\hline Mean & 65 & 43 & 44 & 48 & 51 & 55 & 57 & 78 & 74 & 57 \\
\hline SD & 14 & 9 & 8 & 7 & 6 & 14 & 10 & 24 & 23 & 13 \\
\hline \multicolumn{11}{|c|}{ Total solutes $(\mathrm{mmol} / 24 \mathrm{~h})$} \\
\hline Mean & 880 & 549 & 651 & 753 & 772 & $889(4)$ & 一 & 1179 & $1206(5)$ & 860 \\
\hline SD & 181 & 84 & 134 & 98 & 146 & 156 & 一 & 324 & 671 & 224 \\
\hline \multicolumn{11}{|c|}{ Urinary volume $(1 / 24 \mathrm{~h})$} \\
\hline Mean & $1 \cdot 27$ & $1 \cdot 53$ & $1 \cdot 42$ & $1 \cdot 50$ & $1 \cdot 22$ & $1 \cdot 69$ & $1 \cdot 78$ & 1.98 & $1 \cdot 56$ & $1 \cdot 55$ \\
\hline Range & $\begin{array}{l}0.61 \sim \\
2.68\end{array}$ & $\begin{array}{l}0.55 \sim \\
2.92\end{array}$ & $\begin{array}{l}0.55 \sim \\
2.72\end{array}$ & $\begin{array}{l}0.59 \sim \\
3.42\end{array}$ & $\begin{array}{l}0.53 \sim \\
2.66\end{array}$ & $\begin{array}{l}0.68 \sim \\
3.61\end{array}$ & $\begin{array}{l}0.44 \sim \\
3.49\end{array}$ & $\begin{array}{l}0.79 \sim \\
3.52\end{array}$ & $\begin{array}{l}0.63 \sim \\
2.97\end{array}$ & \\
\hline
\end{tabular}

Numbers in parentheses are number of samples examined; SD = standard deviation; $\dagger=$ estimated from specific gravity and Häser's index.

levels and renal function (PSP test, Fishberg test) at the time of examination are listed in Table 1. Laboratory tests showed that renal function was normal or borderline in every subject. No albumin or glucose was found in any urine sample.

\section{COLLECTION OF URINE SAMPLES}

After maintaining their usual intake of food and water for two days, the subjects drank about 0.251 water each day for another two days, and were then loaded with about 31 water daily for two successive days. Urinary volume, specific gravity, osmolality, and concentrations of lead, ALA, coproporphyrin and creatinine were measured on every 24-h urinary sample. The two-day course of water restriction and water loading, respectively, was chosen because it was expected that the period would cover a wide range of urinary volume with a minimum of discomfort to the subjects examined. In some cases, the whole period of examination ranged from five to ten days.

ANALYTICAL METHODS

Lead concentrations in blood and urine were measured by atomic absorption spectrophotometry (Perkin-Elmer 403) with wet ashing, chelation by ammonium pyrrolidine dithiocarbamate and extraction to water-saturated methyl isobutyl ketone 
(Araki, 1973); urinary ALA concentration was measured by the method of Wada et al. (1969); urinary coproporphyrin by fluorescence spectrophotometry (Hitachi, MPF-2A); creatinine by Jaffe's reaction; osmolality of urine by the freezing point depression method (Fiske Osmometer); and specific gravity of urine by refractometry (Erma Clinical Refractometer). The reproducibility of analysis, when expressed as a coefficient of variation, was
$8 \cdot 2,1 \cdot 1,1 \cdot 3,0 \cdot 5,1 \cdot 7$ and $1.0 \%$ in lead, ALA, coproporphyrin, creatinine, specific gravity and osmolality, respectively. The accuracy of the measurement of blood and urinary lead concentrations was tested several times by double analysis with the Occupational Health Service Centre of the Japan Industrial Safety Association. The difference between both laboratories was within the range of reproducibility of the measurements.
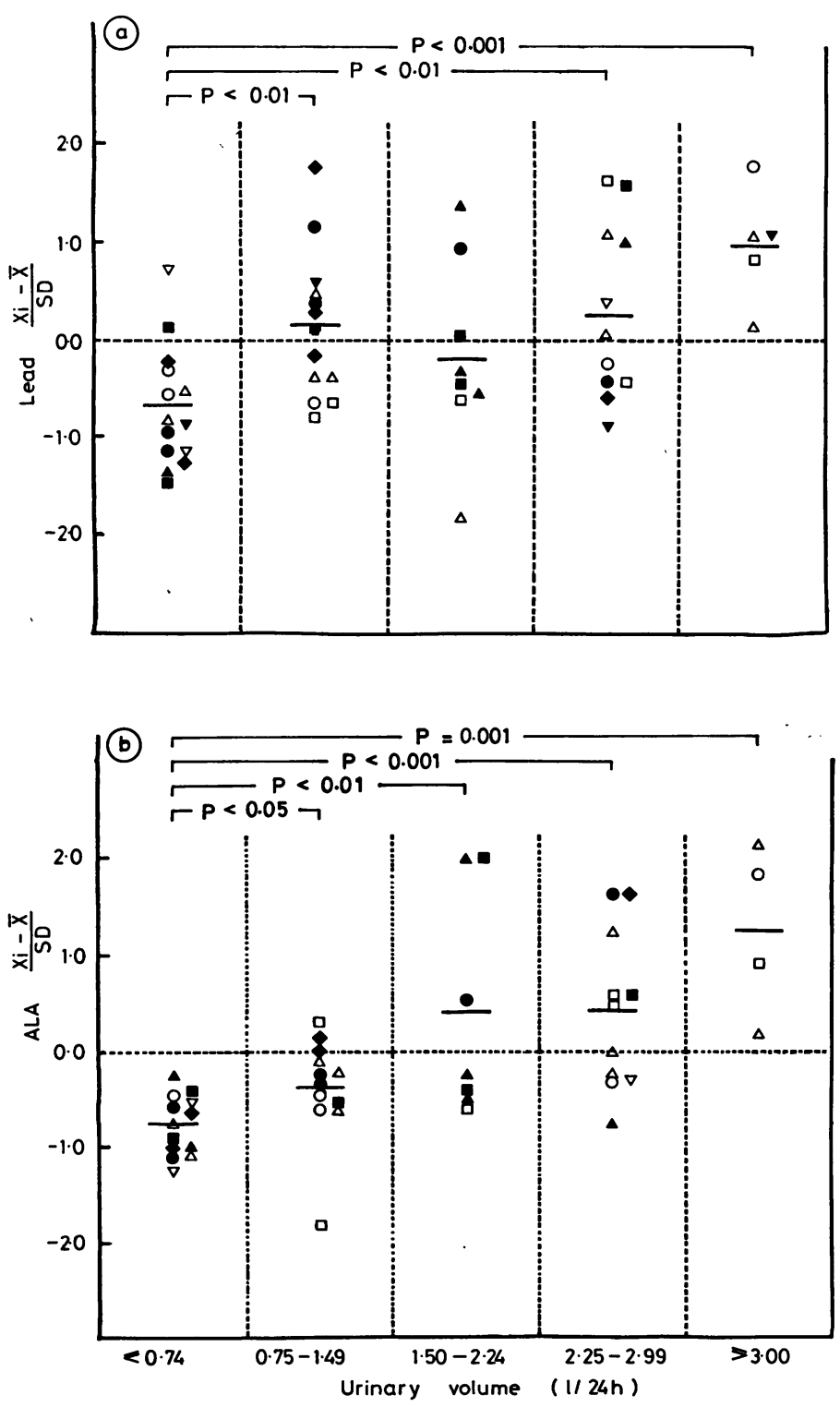

Fig. 1a

Fig. 1 Relationship between urinary volume and 24-hour excretion of (a) lead, (b) ALA and (c) total solutes. $X i, \bar{X}, S D$ and $\frac{X i-\bar{X}}{S D}$ represent

24-hour urinary excretion of the substance examined, mean of $X i$, standard deviation of $X i$ and standardised value of urinary substance, respectively, for each subject. shows Subject A.I.; $\triangle$, G.S.; $\square$, S.O.; $\nabla$, M.O.; $\diamond$, N.T.; O, S.H.; $\triangle, K . K . ;$ $\square, T . S . ;$ and $\nabla, T . N$. The transverse line in each column shows the mean value. $\mathrm{P}=$ significance level for the comparison of two groups by the Wilcoxon rank sum test.

Fig. $1 b$ 


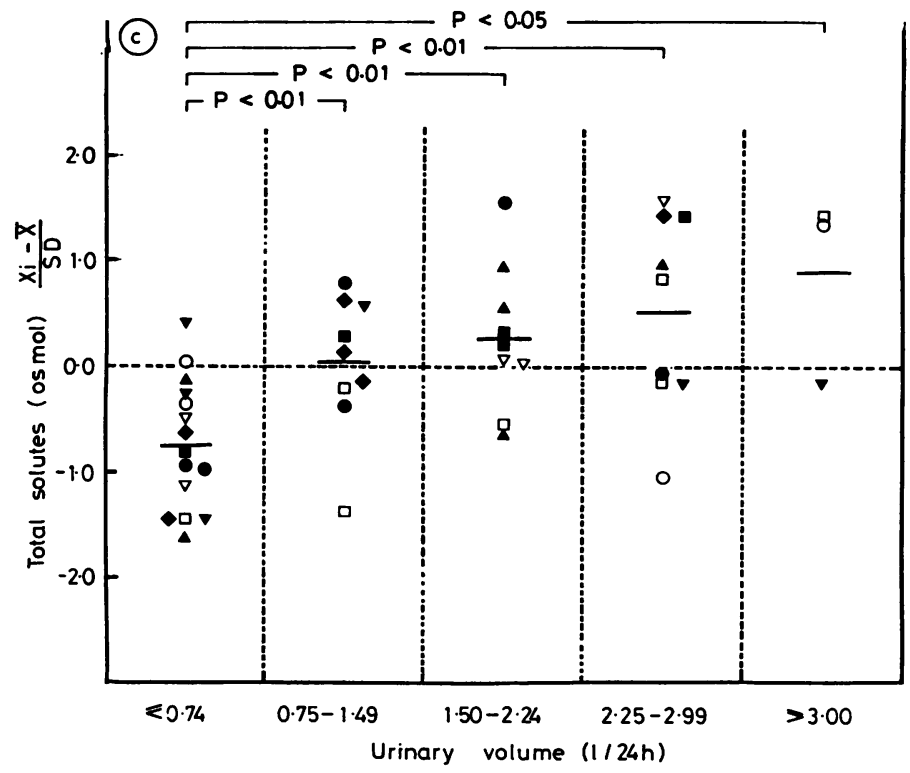

Fig. 1c

STATISTICAL ANALYSIS

The nonparametric method of the Wilcoxon rank sum test was applied for the comparison of two groups with small sample size.

\section{Results}

The daily variation in urinary excretion of lead, ALA, coproporphyrin, creatinine, total solutes and urinary volume in each subject is shown in Table 2. The interindividual variation was standardised by

the formula $\frac{X i-\bar{X}}{S D}$,where $X i, \bar{X}$ and SD represent

the daily excretion of the substance examined, the mean of $\mathrm{Xi}$ and the standard deviation of $\mathrm{Xi}$ in each subject, respectively. The standardised values of all the subjects were plotted against the corresponding urinary volume. The excretion of lead, ALA and total solutes was significantly reduced when urinary volume was less than $0.75 \mathrm{l} / 24 \mathrm{~h}$, and tended to increase with urinary volume (Figs. 1a, b, c). On the other hand the excretion of coproporphyrin and creatinine was constant.

The daily excretion of lead, ALA, coproporphyrin and total solutes was then plotted against the corresponding creatinine excretion. The excretion of these substances was expressed by the formula $\frac{\mathrm{X} i-\overline{\mathrm{X}}}{\mathrm{SD}}$, as before. The excretion of lead and total solutes was significantly reduced when creatinine excretion was lower (below the mean minus standard deviation), and tended to increase in proportion to urinary creatinine excretion (Figs. 2a, b). The excretion of ALA and coproporphyrin was independent of that of creatinine.

\section{Discussion}

In this study it is difficult to consider the possibility of the extramobilisation of lead and other substances from body tissues into the circulation by excessive water intake, because renal plasma flow and glomerular filtration rate are not expected to increase following such an intake. Glomerular filtration rate varies little with body hydration (Renkin and Gilmore, 1973), as shown to some extent by the present study, in which creatinine excretion was not significantly dependent on urinary volume. The regulatory mechanism of the proximal tubule does not seem to be influenced by the amount of filtered fluid, as the reabsorption of water is characterised as iso-osmotic and secondary to active reabsorption of solutes in the proximal tubule (Giebisch and Windhager, 1973). On the other hand, final urinary volume is determined by the net reabsorption of water through the collecting duct which is surrounded by the hypertonic medullary interstitium. The filtered fluid is concentrated there until its osmotic pressure is as high as that of the surrounding fluid in the presence of antidiuretic hormone (ADH). The hormone increases the permeability to water 


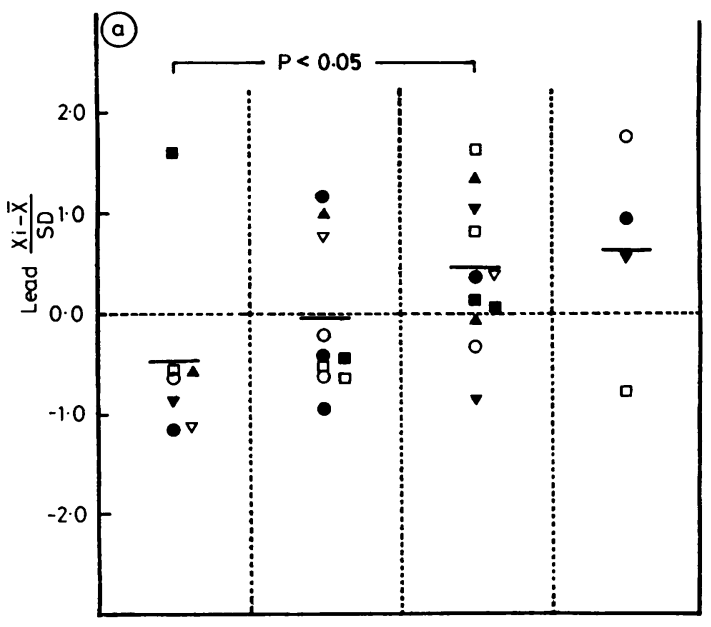

Fig. 2a

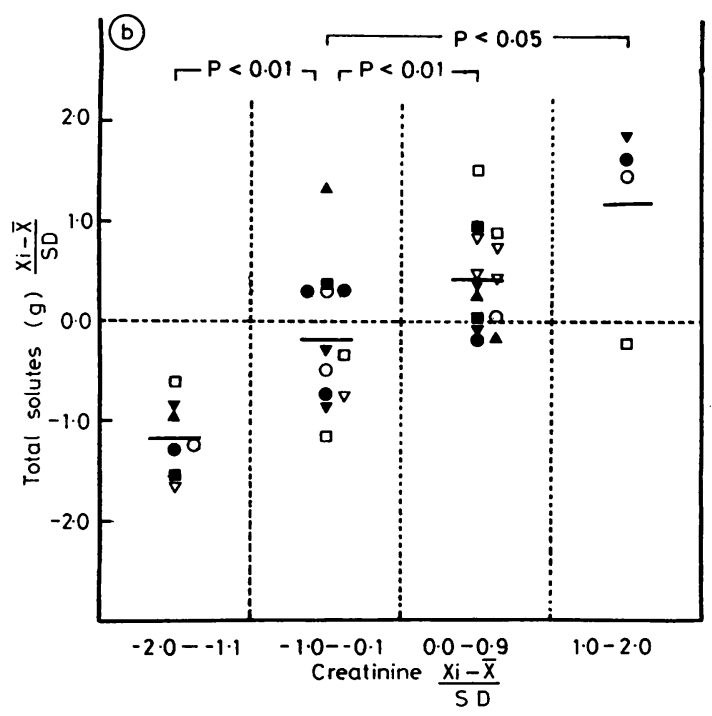

Fig. 2b

Fig. 2 Relationship between creatinine excretion and 24-hour excretion of (a) lead and (b) total solutes. Abbreviations and symbols as in Fig. 1.

of the lining epithelium of the distal convoluted tubule and the collecting duct. Therefore, if the excretion of any urinary substance is affected by urinary volume, it means that the substance undergoes modification mainly by the distal tubule and the collecting duct.

The urinary excretion of creatinine could be considered to be an approximate index of glomerular filtration, though it is reported that creatinine is secreted by the proximal tubule of man to a certain extent (Levinsky and Levy, 1973).

As shown in Fig. 2, the excretion of lead is closely related to that of creatinine. Therefore, lead is considered to be filtered by the glomerulus. This reasoning is supported by an experimental result by Vostál (1963). The decrease of lead excretion corresponding to antidiuresis (Fig. 1) suggests that there is a tubular reabsorptive mechanism under such conditions. The result may not be attributable to decreased renal plasma flow and glomerular filtration rate because creatinine excretion did not significantly decrease under the influence of antidiuresis. Because of the existence of glomerulartubular balance in the proximal tubule (Gertz and Boylan, 1973), the excretion of lead should be determined ultimately by the urinary flow rate through the distal tubule and the collecting duct.

ALA should be reabsorbed, not only actively by the proximal tubule, but also by the distal tubule and the collecting duct. The final urinary excretion of ALA should be related far more to the reabsorptive mechanism of the tubules than to the glomerular filtration. This may explain why ALA was not significantly dependent on creatinine excretion. Coproporphyrin could not be considered either to be filtered by the glomerulus or reabsorbed by the tubules. It should be formed by auto-oxidation of filtered or secreted coproporphyrinogen passing through the urinary tract. Total urinary solutes are filtered by the glomerulus and reabsorbed by the tubules. Their high dependence on urinary volume may be partly due to overloading in the case of overhydration.

The results obtained in this study indicate also that even 24-h urinary samples are not valid for the evaluation of lead absorption under certain circumstances. Similarly, in view of the positive effect of urinary volume on the excretion of lead, ALA and total urinary solutes, and the non-significant effect on that of coproporphyrin and creatinine, it is not considered reasonable to adjust the excretion of lead and ALA to that of urinary creatinine in order to minimise the effect of urinary volume, nor to adjust coproporphyrin to total urinary solutes. Instead, lead and ALA should be adjusted to total urinary solutes, i.e. urinary specific gravity or osmolality. These points will be discussed in another paper.

The author wishes to express his thanks to Dr D. B. Douglas, Honorary Lecturer in Occupational Medicine at the London School of Hygiene and Tropical Medicine, for his advice and kind review of the manuscript. Thanks are also due to $\mathrm{Dr} M$. Nagasaka, Assistant Professor at the University of Tokyo, for his valuable suggestion about renal physiology. 


\section{References}

Araki, S. (1973) On the behaviour of 'active deposit of lead (Teisinger)' in Japanese free from occupational exposure to lead. Industrial Health (Kawasaki), 11, 203-224.

Berlin, N. I., Neuberger, A., and Scott, J. J. (1956). The metabolism of $\delta$-aminolaevulinic acid. 2. Normal pathways, studied with the aid of ${ }^{14} \mathrm{C}$. Biochemical Journal, 64, 90100.

Druyan, R., Haeger-Aronsen, B., Von Studnitz, W., and Waldenström, J. (1965). Renal mechanism for excretion of porphyrin precursors in patients with acute intermittent porphyria and chronic lead poisoning. Blood, 26, 181-188.

Gertz, K. H., and Boylan, J. W. (1973). Glomerular-tubular balance. In Handbook of Physiology, Section 8, pp. 763790. Edited by J. Orloff, R. W. Berliner, and S. R. Geiger. American Physiological Society: Washington, DC.

Giebisch, G., and Windhager, E. E. (1973). Electrolyte transport across renal tubular membranes. In Handbook of Physiology, Section 8, pp. 315-376. Edited by J. Orloff, R. W. Berliner, and S. R. Geiger. American Physiological Society: Washington, DC."

Johnson, D. R., Foulkes, E. C., and Hammond, P. B. (1976). The renal handling of $\delta$-aminolevulinic acid in normal and lead-poisoned rabbits. Toxicology and Applied Pharmacology, 38, 101-109.

Kawai, M. (1976). Urinary non-precipitable lead in lead workers. British Journal of Industrial Medicine, 33, 187192.

Levinsky, N. G., and Levy, M. (1973). Clearance techniques. In Handbook of Physiology, Section 8, pp. 103-117. Edited by J. Orloff, R. W. Berliner, and S. R. Geiger. American Physiological Society: Washington, DC.

Miura, H. (1971). Excretory mechanism of urinary coproporphyrin, with special reference to lead poisoning. Igaku-no Ayumi (Developments in Medical Science), 77, 605-609. (In Japanese.)
Molyneux, M. K. B. (1964). Use of single urine samples for the assessment of lead absorption. British Journal of Industrial Medicine, 21, 203-209.

Renkin, E. M., and Gilmore, J. P. (1973). Glomerular filtration. In Handbook of Physiology, Section 8, pp. 185248. Edited by J. Orloff, R. W. Berliner, and S. R. Geiger. American Physiological Society: Washington, DC.

Sakurai, S., and Kagawa, J. (1973). Correction of urine concentration in spot samples. Japanese Journal of Industrial Health, 15, 567. (In Japanese.)

Suzuki, S., and Suzuki, T. (1974). Inter-relationships of some biochemical indicators of lead absorption with special reference to serum delta-aminolevulinic acid and its renal clearance. Industrial Health (Kawasaki), 12, 37-48.

Suzuki, T., and Suzuki, S. (1966). Liver and kidney porphyrins in experimental lead poisoning of mice and rabbits. Industrial Health (Kawasaki), 4, 56-58.

Taguchi, T., Suzuki, T., Suzuki, S., and Takemoto, T. (1972). Variation in daily urinary excretion of lead, cadmium, delta-aminolevulinic acid and coproporphyrin in five men without occupational exposure to metals. Industrial Health, (Kawasaki), 10, 77-83.

Vostál, J. (1963). Mechanisms of renal lead excretion. Biochemical Pharmacology, Conference Issue, 2, 207. Cited in J. Vostál and J. Heller (1968). Renal excretory mechanisms of heavy metals. 1. Transtubular transport of heavy metal ions in the avian kidney. Environmental Research, 2, 1-10.

Vostál, J., and Heller, J. (1968). Renal excretory mechanisms of heavy metals, 1 . Transtubular transport of heavy metal ions in the avian kidney. Environmental Research, 2, 1-10.

Wada, O., Toyokawa, K., Urata, G., Yano, Y., and Nakao, K. (1969). A simple method for the quantitative analysis of urine delta-aminolevulinic acid to evaluate lead absorption. British Journal of Industrial Medicine, 26, 240-243.

Webster, S. H. (1941). Diurnal variation of urinary lead excretion. Public Health Reports, 56, 1834-1848. 